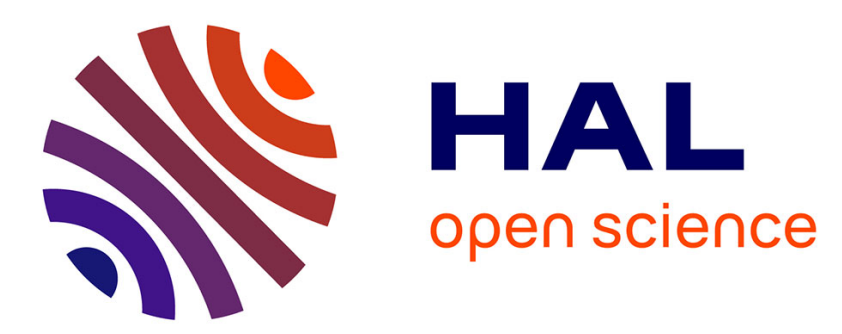

\title{
Signaling-dependent nuclear export of estradiol receptor controls cell cycle progression in breast cancer cells
}

\author{
Gabriella Castoria, Antimo Migliaccio, Ferdinando Auricchio
}

\section{To cite this version:}

Gabriella Castoria, Antimo Migliaccio, Ferdinando Auricchio. Signaling-dependent nuclear export of estradiol receptor controls cell cycle progression in breast cancer cells. Molecular and Cellular Endocrinology, 2009, 308 (1-2), pp.26. 10.1016/j.mce.2009.01.006 . hal-00499110

\section{HAL Id: hal-00499110 https://hal.science/hal-00499110}

Submitted on 9 Jul 2010

HAL is a multi-disciplinary open access archive for the deposit and dissemination of scientific research documents, whether they are published or not. The documents may come from teaching and research institutions in France or abroad, or from public or private research centers.
L'archive ouverte pluridisciplinaire HAL, est destinée au dépôt et à la diffusion de documents scientifiques de niveau recherche, publiés ou non, émanant des établissements d'enseignement et de recherche français ou étrangers, des laboratoires publics ou privés. 


\section{Accepted Manuscript}

Title: Signaling-dependent nuclear export of estradiol receptor controls cell cycle progression in breast cancer cells

Authors: Gabriella Castoria, Antimo Migliaccio, Ferdinando Auricchio

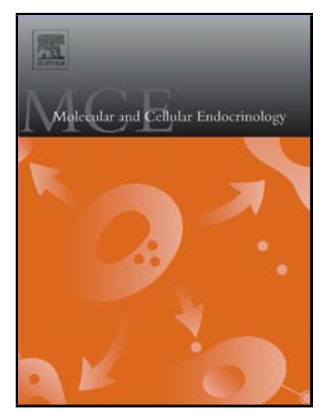

PII:

S0303-7207(09)00033-1

DOI: doi:10.1016/j.mce.2009.01.006

Reference: MCE 7118

To appear in: Molecular and Cellular Endocrinology

Received date: 16-9-2008

Revised date: $12-12-2008$

Accepted date: 6-1-2009

Please cite this article as: Castoria, G., Migliaccio, A., Auricchio, F., Signaling-dependent nuclear export of estradiol receptor controls cell cycle progression in breast cancer cells, Molecular and Cellular Endocrinology (2008), doi:10.1016/j.mce.2009.01.006

This is a PDF file of an unedited manuscript that has been accepted for publication. As a service to our customers we are providing this early version of the manuscript. The manuscript will undergo copyediting, typesetting, and review of the resulting proof before it is published in its final form. Please note that during the production process errors may be discovered which could affect the content, and all legal disclaimers that apply to the journal pertain. 


\title{
ESTRADIOL ACTIVATION OF PI3-K/AKT PATHWAY TRIGGERS ERalpha/FKHR EXPORT IN MAMMARY CANCER CELLS
}

\author{
Gabriella Castoria*, Antimo Migliaccio and Ferdinando Auricchio \\ Department of General Pathology- II University of Naples \\ Via L. De Crecchio, 7 \\ 80138 Napoli (ITALY)
}

* To whom correspondence should be addressed:

Email: gabriella.castoria@unina2.it 


\section{ABSTRACT}

Estradiol receptor plays a key role in breast cancer and specific hormonal therapies blocking the receptor functions have been developed. Unfortunately, many patients become resistant to this treatment and develop metastatic breast tumors. The causes of breast tumor progression and hormonal therapy resistance are still debated. Many proteins are mislocalized in human cancers, and increasing evidence indicates that nuclear exclusion of estradiol receptor is involved in tumorigenesis of breast cancer cells and hormonal therapy resistance. Therefore, analysis of intracellular localization of estradiol receptor together with screening for specific compounds that redirect the mislocalized receptor to the correct subcellular compartment is a very promising approach to the discovery of novel anticancer compounds.

We recently dissected estradiol receptor nuclear export in breast cancer cells and clarified the role of estradiol-activated PI3-K in this process. These findings and their impact on cell cycle progression in breast cancer cells will now be presented. The strategy of trapping estradiol receptor in nuclear compartment of target cells using new peptides mimicking the nuclear export signal of estradiol receptor will also be discussed. 


\section{ESTRADIOL ACTION IN TARGET CELLS}

Estradiol influences many processes in mammals, including cell growth, cardiovascular health, bone integrity, immunity, cognition and behavior. It is well known that transcriptional effects of estradiol usually occur either through ligand-dependent binding of estradiol receptor(s), alpha or beta, to DNA sequences, or receptor association with proteins that in turn bind discrete nucleotide sequences, or the dismissal of co-repressors and recruitment of co-activators (Lonard and O'Malley, 2008). The resulting fluctuations in mRNAs and proteins occur within hours or days following hormonal exposure. Many findings, however, show that regulation of these effects is also mediated by a complex and bidirectional interface between control of gene expression and modulation of signaling cascades activated by estradiol in target cells. Increasing evidence indeed shows that estradiol triggers signaling pathways usually engaged by growth factors, cytokines and extracellular matrix. This so-called 'non-genomic' action is independent of estradiol receptor (ER) transcriptional activity and occurs within seconds or minutes. In addition to estradiol, almost all members of the steroid hormone family, from corticosteroids (glucocorticoids and mineral corticoids) to other sex steroid hormones (progestin and androgens), exert rapid, non-genomic actions. These range from activation of Src, MAPKs, adenylyl cyclase and PI3-K to rises in intracellular-calcium concentrations. Depending on the cell context, these signals are related to different effects of steroid hormones, such as proliferation, survival, vasorelaxation, migration and differentiation (Cheskis et al., 2007 and refs therein).

Our lab has in the past made a major contribution to the understanding of how the estradiolstimulated signaling machinery works, with a specific focus on the interface between intracellular signaling and cell cycle progression. Particularly, we have identified and characterized ER/Src interaction, which plays an important role in the signaling network activated by estradiol, and intersects PI3-K signaling in breast cancer cells (Migliaccio et al., 1996 and 2000; Castoria et al., 2001). This network controls cell cycle progression in cultured MCF-7 cells (Castoria et al., 1999, 2001 and 2004) and cell growth in mouse models of tumorigenesis (Varricchio et al., 2007). Subsequent studies from our and other labs extended these findings to androgens and progestin in other cell types and to a rather complex signaling network (Cato et al., 2002 and refs therein).

This model of steroid hormone action underlines the proliferative role of the rapid hormonal action and the associated mechanisms depending on extra-nuclear localization of the classical steroid receptors. There is therefore a strong interest in defining links between signal transducing pathways and subcellular steroid receptor localization. 


\section{ESTRADIOL RECEPTOR TRAFFICKING}

Although ER is principally localized in nuclei of target cells (Stenoien et al., 2001), it has been reported that ER continuously shuttles between nuclei and cytoplasm, and that the antiestrogens ICI 182780 disrupts this process (Dauvois et al., 1993). In addition, cellular conditions, ligand binding and protein-protein interactions can significantly influence the nucleocytoplasmic shuttling of ER (Pemberton \& Paschal, 2005 and refs therein).

Ligand stimulation of different cell types recruits different signaling effectors to ERalpha or ERbeta, which in turn leads to signal transduction pathway activation (Song \& Santen, 2006 and refs therein). In addition, a transcriptional incompetent ERalpha mutant permanently resides in cytoplasm and mediates S-phase entry triggered by estradiol activation of the Src/Ras/ERK pathway (Castoria et al., 1999; Lombardi et al., 2008). These findings indicate a proliferative function for this extra-nuclear receptor, which is independent of its nuclear localization and transcriptional activity.

Many events regulate ER localization and their derangement causes ER mislocalization and tumor progression. PRMT1-mediated ERalpha methylation is required for recruitment of Src, PI3-K and FAK to ERalpha, and a subset of human breast cancer shows high levels of methylated ERalpha that is exclusively localized in the cytoplasm (Le Romancer et al., 2008). The recently discovered cytoplasmic cross talk between ER and EGF signaling in breast cancer MCF-7 cells (Migliaccio et al., 2005) has therefore emerged as a critical factor in endocrine resistance through the control of subcellular localization of ER signaling components (Gururaj et al., 2006). In addition to mediating Src recruitment to ER, association of the receptor with the adaptor protein MNAR (Wong et al., 2002) also plays a role in ER localization. MNAR sequesters ER in cytoplasm/membrane, thus enhancing non-genomic effects of ER (Vadlamudi et al., 2005). Tumorigenesis and anti-hormone resistance of breast cancer cells then follow (Vadlamudi et al., 2005; Gururaj et al., 2006). Furthermore, expression of a shortened form of the metastatic tumor antigen 1 (MTA1s) sequesters ER in the cytoplasm and leads to malignant phenotypes by enhancing ER cytoplasmic functions in hormone-dependent breast cancer cells (Kumar et al., 2002).

These findings imply that cytoplasmic localization of ER provides a mechanism to control signal transduction-dependent functions, such as DNA synthesis and anchorage-dependent growth of target cells. They also suggest that ER localization has functional implications in breast cancer progression and endocrine resistance. However, new information on the molecular basis of ERalpha nuclear export is emerging, and the combined import-export cycle of ER can be viewed as a potential mechanism for transcription integration with signaling events initiated in the cytoplasm. 


\subsection{ESTRADIOL RECEPTOR NUCLEAR EXPORT: THE ROLE OF CRM1}

Whereas it is largely accepted that steroid receptors undergo ligand-dependent nuclear translocation, the mechanism of their nuclear export is as yet unclear. The best-characterized nuclear export pathway uses CRM1 as a receptor for proteins with leucine-rich nuclear export signals (NESs; Fornerod et al., 1997; Fukuda et al., 1997). Leptomycin B (LMB), through covalent binding to CRM1, inhibits CRM1-dependent nuclear export (Kudo et al., 1998). Conflicting data have been reported on inhibition of steroid receptor nuclear export by LMB treatment. Steroid receptors lack classical hydrophobic leucine-rich NESs, but have sequences with limited homology to NESs (De Franco, 2001). In addition, they can interact with other proteins, such as 14-3-3 family members and p160 co-activators that contain the nuclear export signals and function as adapters for CRM1-dependent export of steroid receptors. Under some conditions, LMB treatment inhibits the nuclear export of these receptors (Pemberton \& Paschal 2005, and refs therein).

We recently dissected the nucleo-cytoplasmic shuttling of chimeric ERalpha in MCF-7 cells, focusing on its export from the nucleus. Estradiol treatment of quiescent cells induces nuclear translocation of ERalpha after $30 \mathrm{~min}$, followed by a decrease in the nuclear receptor to the basal level within $1 \mathrm{~h}$. Using LMB as well as in vitro interaction assay, we discovered that hormone-bound ERalpha is exported from nuclei through the CRM1/exportin pathway. LMB treatment of MCF-7 cells prevents ERalpha nuclear export in $1 \mathrm{~h}$ estradiol-treated cells, and the hormone induces a strong interaction between recombinant ERalpha and in vitro translated CRM1 (Lombardi et al., 2008).

Thus, we showed by a nuclear export assay that the leucine-rich 444-456 sequence of ERalpha contains a functional NES, which is sensitive to LMB treatment (Lombardi et al., 2008). A Tat-conjugated peptide mimicking this amino acid sequence specifically retains ERalpha in the nuclear compartment of $1 \mathrm{~h}$ estradiol-treated MCF-7 cells (Fig. $1 \mathrm{~A}$ ) and displaces the interaction between ERalpha and CRM1 in vitro (Lombardi et al., 2008). These findings support the conclusion that the $444-456$ sequence contains a putative NES. In addition, mutations in the core of this sequence impair the estradiol-induced nuclear export of full-length ERalpha in MCF7 cells (Fig. 1B). The 444-456 sequence we mapped in the hormone-binding domain of ERalpha is conserved among the members of a steroid receptor family, such as ERbeta, progesterone receptor $(\mathrm{PgR})$, androgen receptor $(\mathrm{AR})$, glucocorticoid receptor $(\mathrm{GR})$ and mineral corticoid receptor (MR). This homology suggests that such a sequence is responsible for CRM1dependent nuclear export of most steroid receptors (Lombardi et al., 2008).

By combining different approaches, we linked ERalpha nuclear export to DNA synthesis triggered by estradiol in target cells. The Tat-conjugated peptide we used to trap ERalpha in the nuclear compartment of MCF-7 cells (Fig. 1A) specifically reduces estradiol-induced S-phase entry in MCF-7 cells (Fig. 1C). Furthermore, the NES-ERalpha mutant ectopically expressed in 
NIH3T3 fibroblasts fails to induce S-phase entry (Fig. 1D), whereas it activates gene transcription upon estradiol treatment of cells (Lombardi et al., 2008).

Altogether, these findings point to the role of ERalpha nuclear export in estradiol-regulated DNA synthesis in breast cancer cells.

\subsection{ESTRADIOL RECEPTOR NUCLEAR EXPORT: THE ROLE OF PI3-K/AKT PATHWAY}

There is substantial interest in defining how signal transduction pathways contribute to nuclear receptor localization. Nuclear import of $\mathrm{GR}$, for instance, can be triggered by shear stress activation of MAPK and PI3-K (Ji et al., 2003), and MAPKs have also been implicated in the regulation of PgR and GR nuclear export (Shank and Paschal, 2005). Furthermore, EGFstimulated MAPK phosphorylates $\mathrm{PgR}$, thus inducing nuclear exclusion and cytoplasmic degradation of PgR (Qiu et al., 2003).

We recently observed a new link between estradiol activation of PI3-K/AKT pathway and the nuclear export of ERalpha. Fig. 2 ( $A$ and $B$ ) shows that over-expression of dominant-negative versions of p85alpha, the regulatory subunit of PI3-K, and AKT inhibits $1 \mathrm{~h}$ estradiol-induced ERalpha nuclear export in MCF-7 cells, thus linking a rapid action of estradiol controls with ERalpha intracellular traffic.

Previous findings reported that FKHR nuclear export depends on its phosphorylation by AKT (Biggs et al., 1999), and data from our lab showed that estradiol activation of the PI3-K/AKT pathway is required to drive MCF-7 cells into S phase (Castoria et al., 2001). In addition, an estradiol-dependent interaction between ERalpha and FKHR forkhead () has been described (Schuur et al., 2001). Altogether, these findings lead us to hypothesize a role for FKHR in both estradiol-regulated ERalpha nuclear export and cell cycle arrest mediated by NES-ERalpha mutant.

We have recently shown that estradiol-activated PI3-K/AKT pathway leads to phosphorylation of the gatekeeper Ser 256 of FKHR in MCF-7 cells. In addition, it has been observed that expression of the FKHR mutant (FKHR-AAA), which cannot be phosphorylated by AKT, localizes in nucleus thereby inducing G1 arrest in cells (Nakamura et al., 2000). Expression of this unphosphorytable mutant inhibits the estradiol-induced S-phase entry in MCF-7 cells (Lombardi et al., 2008). Interestingly, over-expression of this mutant sequesters ERalpha in the nuclear compartment of $1 \mathrm{~h}$ estradiol-treated MCF-7 cells (Fig. 2C). In turn, over-expression of NES-ERalpha mutant retains wild type FKHR in the nuclei at that time (Fig. 2D). Thus, estradiol simultaneously regulates ER and FKHR nuclear export. Since ERalpha knockdown by siRNA traps wild type FKHR in the nuclear compartment of $1 \mathrm{~h}$ estradiol-treated MCF-7 cells, we concluded that in ERalpha-positive breast cancer cells FKHR moves from nucleus to cytoplasm via receptor-dependent mechanism (Lombardi et al., 2008). These findings are corroborated by immunoprecipitation experiments showing that 30-min estradiol stimulation increases the association of wild type FKHR with ERalpha in MCF-7 cells. In the same experimental setting, 
the mutant FKHR-AAA fails to do so (Fig. 2E). Thus, FKHR phosphorylation by estradiol is required for its association with receptor, the export of the FKHR/ER complex and the consequent release of FKHR-mediated cell cycle inhibition.

FKHR belongs to the FoxO subfamily of forkhead transcription factors that are negatively regulated by $\mathrm{PI}-\mathrm{K} / \mathrm{AKT}$ pathway, and AKT exerts its proliferative effect both by induction of cyclin D1 and down-regulation of p27 expression. FoxO factors downregulate cyclin D1 and upregulate p27 expression (Medema et al., 2000; Schmidt et al., 2002; Ramaswamy et al., 2002). In both cases, a transcriptional regulation mechanism seems to be involved so that cell cycle is stopped. Such inhibition is released upon FoxO phosphorylation by AKT (Birkenkamp \& Coffer, 2003 and refs therein). Our findings, together with previous data on induction of cyclin D1 transcription by estradiol-activated PI3-K/AKT pathway in MCF-7 cells (Castoria et al., 2001), led us to hypothesize the model depicted in Fig. 3. According to this model, estradiol stimulation of the PI3-K/AKT pathway triggers FKHR phosphorylation and leads to the functionally associated export of FKHR-ERalpha complex. In this way, the inhibitory action of FKHR on cyclin D1 transcription is removed and breast cancer cells enter $S$ phase. Impairment of ER nuclear export by site-directed mutagenesis of NES-ER or interference in the ER/CRM1 interaction by synthetic peptides inhibits FKHR export and blocks cell cycle progression.

In summary, our data reveal a novel link between non-genomic estradiol action and ER export, and identify a new role for ER in DNA synthesis. It is plausible that alterations in nuclear trafficking of steroid receptors influence proliferation and contribute to human proliferative diseases. Therefore, a detailed analysis of nuclear transport pathways and regulation of this process is expected to provide new insights into how subcellular compartmentalization contributes to cell regulation in both normal and patho-physiological states. Lastly, these findings support the notion that nuclear retention of ERalpha essentially antagonizes the proliferative action of the PI3-K/AKT pathway. This pathway is frequently deregulated in human cancers as a consequence of inactivation of the tumor suppressor PTEN (Di Cristofano \& Pandolfi, 2000), or constitutive activation of AKT (Testa \& Bellacosa, 2001). In this respect, the strategy of trapping ER in the nuclear compartment may make an important contribution to the development of novel therapeutic strategies for human breast cancers that result from constitutive activation of the PI3-K/AKT pathway (Dillon et al., 2007 and refs therein). 


\section{ACKNOWLEDGEMENTS}

This work was supported by grants from Associazione Italiana per la Ricerca sul Cancro (National and Regional Grants), Ministero dell'Università e della Ricerca Scientifica (PRIN 2006) and Regione Campania (Legge 5).

The authors declare that they do not have competing financial interests. 


\section{ABBREVIATIONS LIST}

$A R$, androgen receptor; CRM1, chromosome region maintenance 1; EGF, epidermal growth factor; EGFR, epidermal growth factor receptor; ER, estradiol receptor; FKHR, forkhead in rhabdomyosarcoma; GFP, green fluorescent protein; GR, glucocorticoid receptor; LMB, leptomycin B; MAPK, mitogen activated protein kinase; MNAR, modulator of non-genomic action of steroid receptors; MR, mineralcorticoid receptor; MTA1, metastatic tumor antigen; NES, nuclear export signal; PgR, progesterone receptor; PI3-K, phosphatidylinositol-3-kinase; PKC, protein kinase C; PTEN, phosphatase and tensin homologue deleted on chromosome. 


\section{REFERENCES}

Biggs, W.H. 3rd, J. Meisenhelder, T. Hunter, W.K. Cavenee and K.C. Arden. 1999. Protein kinase B/Akt-mediated phosphorylation promotes nuclear exclusion of the winged helix transcription factor FKHR1. Proc. Natl. Acad. Sci. U. S. A. 96: 7421-7426.

Birkenkamp, K.U. and P.J Coffer. 2003. Regulation of cell survival and proliferation by the FOXO (Forkhead box, class O) subfamily of Forkhead transcription factors. Biochem. Soc. Trans. 31: 292-297.

Castoria, G., M.V. Barone, M. Di Domenico, A. Bilancio, D. Ametrano, A. Migliaccio and F. Auricchio. 1999. Non-transcriptional action of estrogen and progestin triggers DNA synthesis. EMBO J. 18: 2500-2510.

Castoria, G., A. Migliaccio, A. Bilancio, M. Di Domenico, A. de Falco, M. Lombardi, R. Fiorentino, L. Varricchio, M.V. Barone and F. Auricchio. 2001. PI3-kinase in concert with Src promotes the S-phase entry of estradiol-stimulated MCF-7 cells. EMBO J. 20: 6050-6059.

Castoria, G., M. Lombardi, M.V. Barone, A. Bilancio, M. Di Domenico, D. Bottero, F. Vitale, A. Migliaccio and F. Auricchio. 2003. Androgen-stimulated DNA synthesis and cytoskeletal changes in fibroblasts by a nontranscriptional receptor action. J. Cell Biol. 161: 547-556.

Castoria, G., A. Migliaccio, M. Di Domenico, M. Lombardi, A. de Falco, L. Varricchio, A. Bilancio, M.V. Barone and F. Auricchio (2004) Role of atypical PKC in estradiol-triggered G1/S progression of MCF-7 cells. Mol. Cell. Biol. 24: 7643-7653.

Cato, A.C., Nestl, A., Mink, S. (2002) Rapid actions of steroid receptors in cellular signaling pathways. Sci STKE. 138: RE9.

Cheskis, B.J., Greger, J.G., Nagpal, S. and Freedman, L.P. 2007. Signaling by estrogens. J. Cell. Physiol. 213: 610-617.

Dauvois, S., R. White and M.G. Parker.1993. The antiestrogen ICl 182780 disrupts estrogen receptor nucleocytoplasmic shuttling. J. Cell. Sci. 106: 1377-1388.

DeFranco D. B. 2001. Nuclear export: DNA-binding domains find a surprising partner. Curr Biol. 11: $1036-1037$.

Di Cristofano, A., and Pandolfi, P.P. 2000. The multiple roles of PTEN in tumor suppression. Cell 100:387-390. 
Dillon, R.L., White, D.E., Muller, W.J. (2007) The phosphatidyl inositol 3-kinase signaling network: implications for human breast cancer. Oncogene 26:1338-1345.

Fornerod M, M. Ohno, M. Yoshida, I.W. Mattaj. 1997. CRM1 is an export receptor for leucinerich nuclear export signals. Cell. 19: 1051-1060.

Fukuda, M., S. Asano, T. Nakamura, M. Adachi, M. Yoshida, M. Yanagida and E. Nishida. 1997. CRM1 is responsible for intracellular transport mediated by the nuclear export signal. Nature 20: 308-311.

Gururaj, A.E., S.K. Rayala, R.K. Vadlamudi, and R. Kumar. 2006. Novel mechanisms of resistance to endocrine therapy: genomic and nongenomic considerations. Clin. Cancer Res. 12: 1001s-1007s.

Ji, J.Y., Jing, H. and Diamond, S.L. 2003. Shear stress causes nuclear localization of endothelial glucocorticoids receptor and expression from the GRE promoter. Circ Res. 92: 279285.

Kumar, R., R.A. Wang, A. Mazumdar, A.H. Talukder, M. Mandal, Z. Yang, R. Bagheri-Yarmand, A. Sahin, G. Hortobagyi, L. Adams, C.J. Barnes and R.K. Vadlamudi. 2002. A naturally occurring MTA1 variant sequesters oestrogen receptor-alpha in the cytoplasm. Nature. 418: $654-657$.

Kudo, N., B. Wolff, T. Sekimoto, E.P. Schreiner, Y. Yoneda, M. Yanagida, S. Horinouchi, and M. Yoshida, 1998. Leptomycin B inhibition of signal-mediated nuclear export by direct binding to CRM1. Exp Cell Res. 242: 540-547.

Le Romancer, M., Treilleux, I., Leconte, N., Robein-Lespinasse, Y., Sentis, S., BouchekiouaBouzaghou, K., Goddard, S., Gobert-Gosse, S. and Corbo, L. 2008. Regulation of estrogen rapid signaling through arginine methylation by PRMT1. Mol. Cell 31, 212-221.

Lombardi, M., Castoria, G., Migliaccio, A., Barone, M.V., Di Stasio, R., Ciociola, A., Bottero, D. Yamaguchi, H., Appella, E. and Auricchio, F. 2008. Hormone-dependent nuclear export of estradiol receptor and DNA synthesis in breast cancer cells. J. Cell Biol. 182: 327-340.

Lonard, D.M. \& O'Malley, B.W. 2008 Gene transcription: two worlds merged. Nature 452: 946947.

Medema, R.H., Kops, G.J., Bos, J.L. and Burgering, B.M. 2000. AFX-like Forkhead transcription factors mediate cell-cycle regulation by Ras and PKB through p27 ${ }^{\text {kip1 }}$. Nature 404: 782-787. 
Migliaccio, A., Di Domenico, M., Castoria, G., de Falco, A., Bontempo, P., Nola, E. and Auricchio, F. 1996. Tyrosine kinase/p21ras/MAP-kinase pathway activation by estradiol-receptor complex in MCF-7 cells. EMBO J. 15: 1292-1300.

Migliaccio, A., Piccolo, D., Castoria, G., Di Domenico, M., Bilancio, A., Lombardi, M., Gong, W., Beato, M. and Auricchio, F. 1998. Activation of the Src/p21ras/Erk pathway by progesterone receptor via cross-talk with estrogen receptor. EMBO J. 17: 2008-2018.

Migliaccio, A., G. Castoria, M. Di Domenico, A. de Falco, A. Bilancio, M. Lombardi, M. V.Barone, D. Ametrano, M.S. Zannini, C. Abbondanza and F. Auricchio .2000. Steroidinduced androgen receptor-oestradiol receptor beta Src complex triggers prostate cancer cell proliferation. EMBO J. 19:5406-5417.

Migliaccio, A. , M. Di Domenico, G. Castoria, M. Nanayakkara, M. Lombardi, A. de Falco, A. Bilancio, L. Varricchio, A. Ciociola, and F. Auricchio. 2005. Steroid receptor regulation of EGF signaling through Src in breast and prostate cancer cells: steroid antagonist action. Cancer Res. 65: 10585-10593.

Migliaccio, A., L. Varricchio, A. De Falco, G. Castoria, C. Arra, H. Yamaguchi, A. Ciociola, M. Lombardi, R. Di Stasio, A. Barbieri, A. Baldi, M. V. Barone, E. Appella, and F. Auricchio. 2007. Inhibition of the SH3 domain-mediated binding of Src to the androgen receptor and its effect on tumor growth. Oncogene 26:6619-6629.

Nakamura, N., S. Ramaswamy, F. Vazquez, S. Signoretti, M. Loda, and W.R. Sellers. 2000. Forkhead transcription factors are critical effectors of cell death and cell cycle arrest downstream of PTEN. Mol. Cell. Biol. 20:8969-8982.

Pemberton, L.F. \& Paschal, B.M. 2005. Mechanisms of receptor-mediated nuclear import and nuclear export. Traffic 6: 187-198.

Qiu, M., Olsen, A., Faivre, E., Horwitz, K.B. and Lange, C.A. 2003 Mitogen-activated protein kinase regulates nuclear association of human progesterone receptor. Mol. Endocrinol. 17: 628-642.

Ramaswamy, S., Nakamura, N., Sansal, I., Bergeron, L. and Sellers, W.R. 2002. A novel mechanism of gene regulation and tumor suppression by the transcription factor FKHR. Cancer Cell 2: 81-91. 
Schmidt, M., de Mattos, S.F., van der Horst, A., Klompmaker, R., Kops, G.J.P.L, Lam, E. W.F, Burgering, B.M.T, Medema, R.H. 2002. Cell cycle inhibition by FoxO forkhead transcription factors involves downregulation of cyclin D1. Mol. Cell. Biol. 22: 7842-7852.

Schuur, E.R., A.V. Loktev, M. Sharma, Z. Sun, R.A. Roth, and R.J. Weigel. 2001 Liganddependent interaction of estrogen receptor-alpha with members of the forkhead transcription factor family. J Biol. Chem. 276:33554-33560.

Shank, L.C. \& Paschal, B.M. 2005. Nuclear transport of steroid hormone receptors. 2005. Crit. Rev. Eukaryot. Gene Expr. 15: 49-73.

Stenoien, D.L., K. Patel, M.G. Mancini, M. Dutertre, C. L. Smith, B.W. O'Malley. and M.A. Mancini. 2001. FRAP reveals that mobility of oestrogen receptor-alpha is ligand- and proteasome-dependent. Nat. Cell. Biol. 3:15-23.

Song, R.X.D. and Santen, R.J. 2006. Membrane initiated estrogen signaling in breast cancer. Biol. Reprod. 75: 9-16.

Testa, J.R. and Bellacosa, A. 2001. AKT plays a central role in tumorigenesis. Proc. Natl. Acad. Sci. U.S.A. 98: 10983-10985.

Vadlamudi, R.K., B. Manavathi, S. Balasenthil, S.S. Nair, Z. Yang, A.A. Sahin, and R. Kumar. 2005. Functional implications of altered subcellular localization of PELP1 in breast cancer cells. Cancer Res. 65:7724-7732.

Varricchio, L., A. Migliaccio, G. Castoria, H. Yamaguchi, A. de Falco, M. Di Domenico, P. Giovannelli, W. Farrar, E. Appella, and F. Auricchio. 2007. Inhibition of Estradiol Receptor/Src Association and Cell Growth by an Estradiol Receptor \{alpha\} Tyrosine-Phosphorylated Peptide. Mol. Cancer Res. 11:1213-1221.

Wong, C.W., McNally, C., Nickbarg, E., Komm, B. S. and Cheskis, B. J. 2002. Estrogen receptor-interacting protein that modulates its nongenomic activity-crosstalk with Src/Erk phosphorylation cascade. Proc. Natl. Acad. Sci. U.S.A. 99: 14783-14788. 


\section{FIGURE LEGENDS}

Fig. 1 Inhibition of estradiol-induced nuclear export and DNA synthesis by a Tat-peptide or mutagenesis of NES-ERalpha full length.

Inset in A shows the sequence of the Tat-conjugated ERalpha (444-456) peptide (Tat-pep) Panels $A$ and $C$ show that the peptide retains the chimeric GFP-ERalpha in the nuclear compartment of $1 \mathrm{~h}$-estradiol treated MCF-7 cells (A) and reduces the estradiol-induced BrdU incorporation in the same cells $(C)$. Panels $B$ and $D$ show that the chimeric GFP-NES-ERalpha mutant does not exit nuclei in MCF-7 cells (B) and does not mediate S-phase entry triggered by estradiol in NIH3T3 fibroblasts (D). Inset in B shows the wild type NES-ERalpha (in bold) endowed in the amino acid 444-456 sequence, together with the mutant NES-ERalpha. Mutated amino acids are underlined.

Fig. 2. Role of estradiol-activated PI3-K/AKT pathway in nuclear export of ER and FKHR. Panel A shows that expression of dominant negative forms of PI3-K $(\Delta \mathrm{p} 85 \alpha)$ and AKT (AKT K $\mathrm{K}^{-}$; dnAKT) retains ERalpha in nuclei of 60 -min estradiol-treated MCF-7 cells. Images of one experiment with dn AKT are presented in B. In cells over-expressing dnAKT (green), the ERalpha (red) is localized in nuclei. Merged images are also presented. In C, over-expression of the mutant GFP-FKHR AAA traps ERalpha in the nuclei of 60-min hormone-treated cells. In D, the Myc tagged-NES-ERalpha mutant retains FKHR in nuclei of 60 min estradiol -treated cells. Panel $E$ shows that 30 min estradiol treatment increases FKHR wt association with ERalpha in MCF-7 cells. Under the same conditions, the mutant FKHR AAA does not associate with ERalpha.

\section{Fig. 3. Model of ERalpha nuclear export.}

The model of ERalpha nuclear export in MCF-7 cells is depicted. Estradiol-stimulated PI3K/AKT pathway leads to FKHR phosphorylation, thus triggering the associated export of FKHR/ER. Such an export removes the transcriptional repressor activity of FKHR on cyclin D1 promoter and fosters the DNA synthesis. This model is fully compatible with our previous findings on regulation of cyclin D1 transcription by estradiol-activated PI3-K/AKT pathway in MCF-7 cells. 
A

Tat-peptide

AC-EFVCLKSIILLNS-AAA-RKKRRQRRR-NH ${ }_{2}$

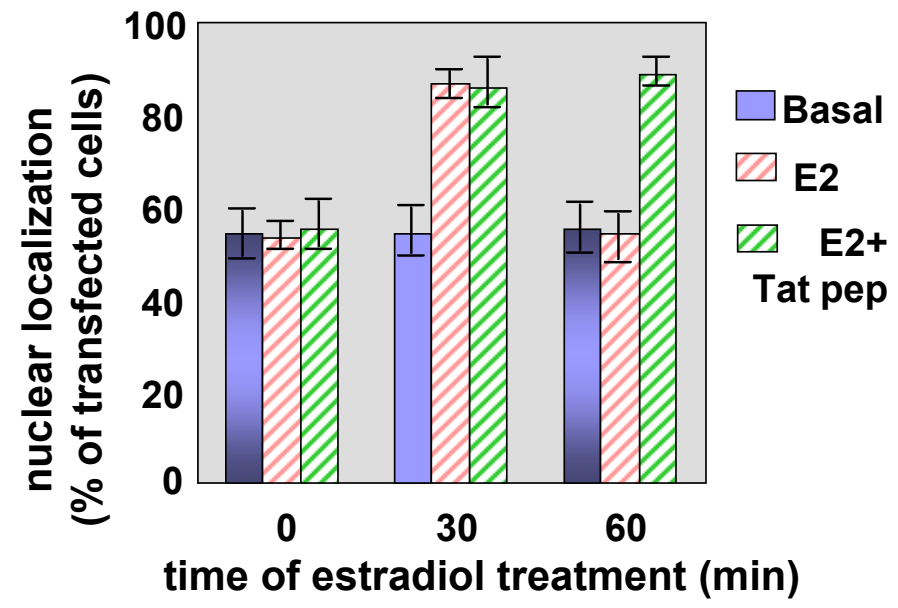

C

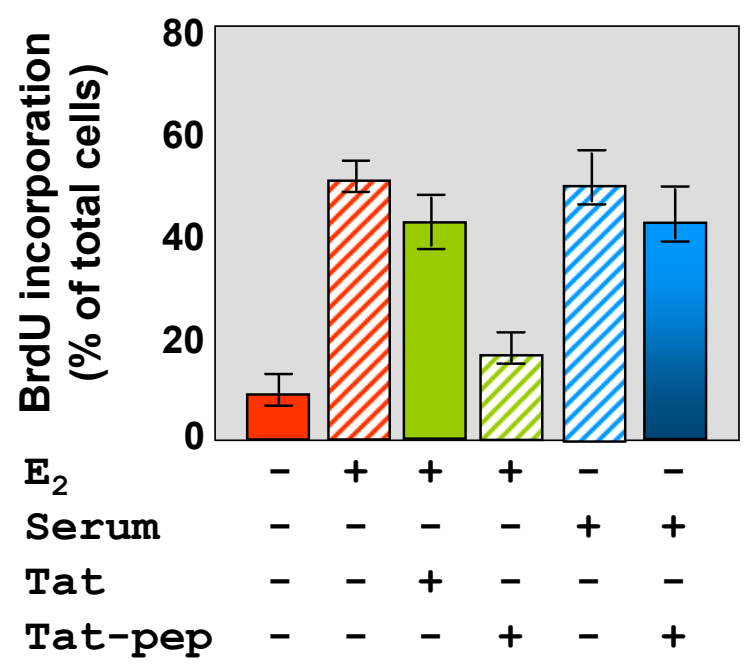

B

\section{GFP-NES ER $\alpha$ wt EFVCLKSIILLNS GFP-NES ER $\alpha$ mut EFVCLKSIALA-}

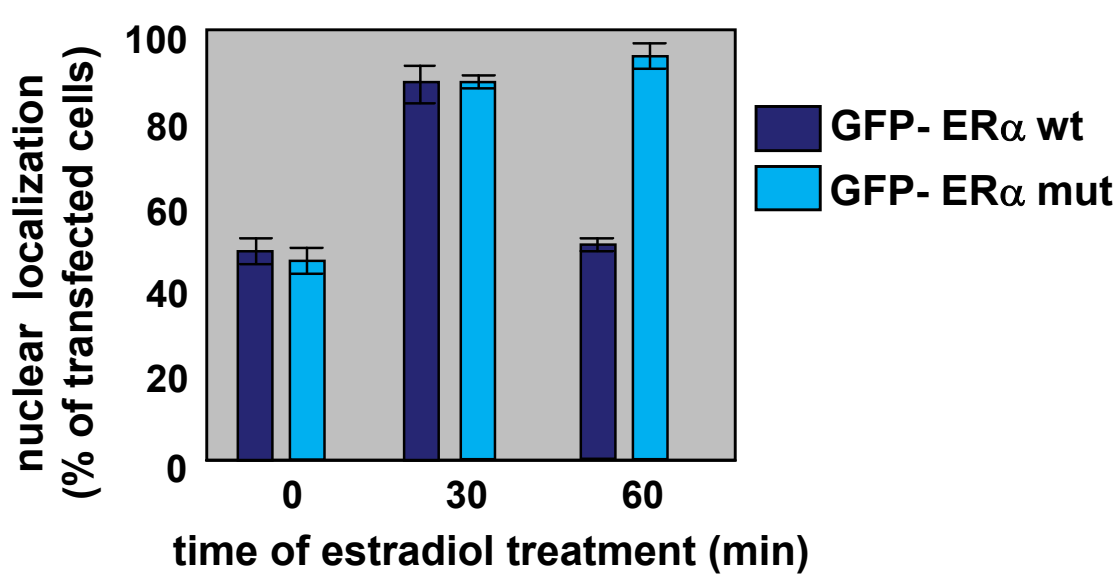

D

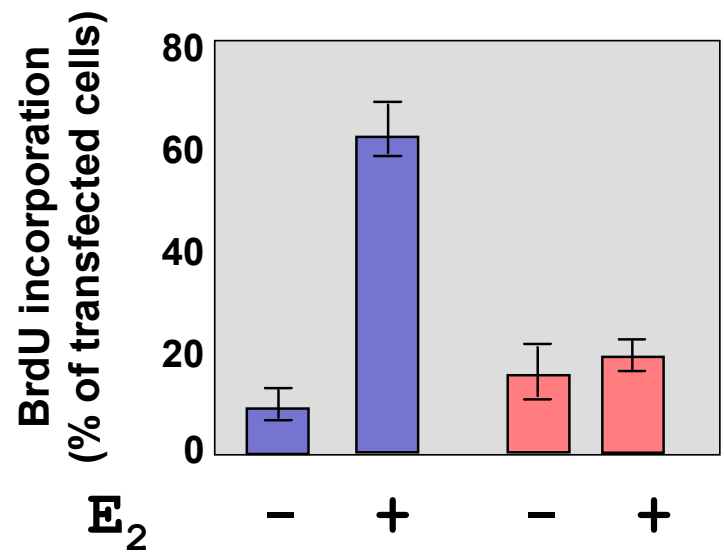

GFP- ER $\alpha$ wt
GFP- ER $\alpha$ mut

Fig. 1 
A

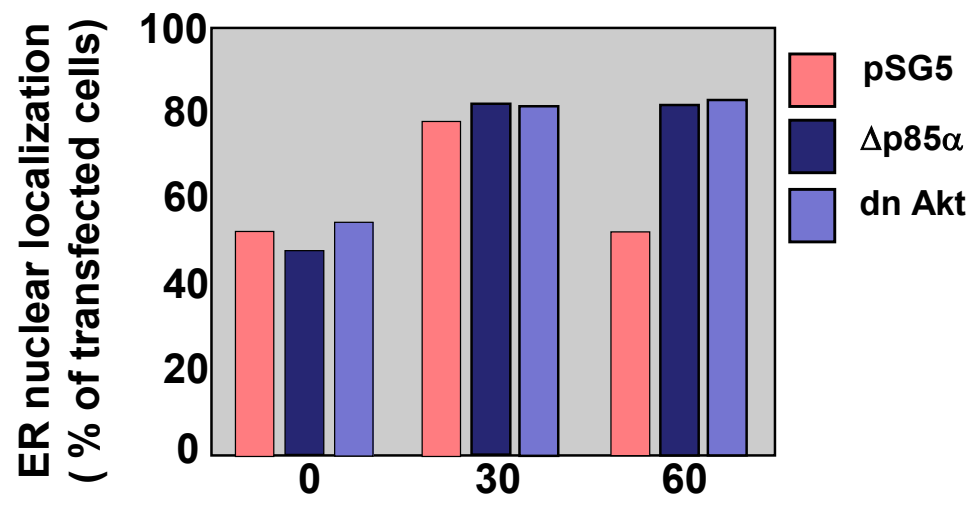

C

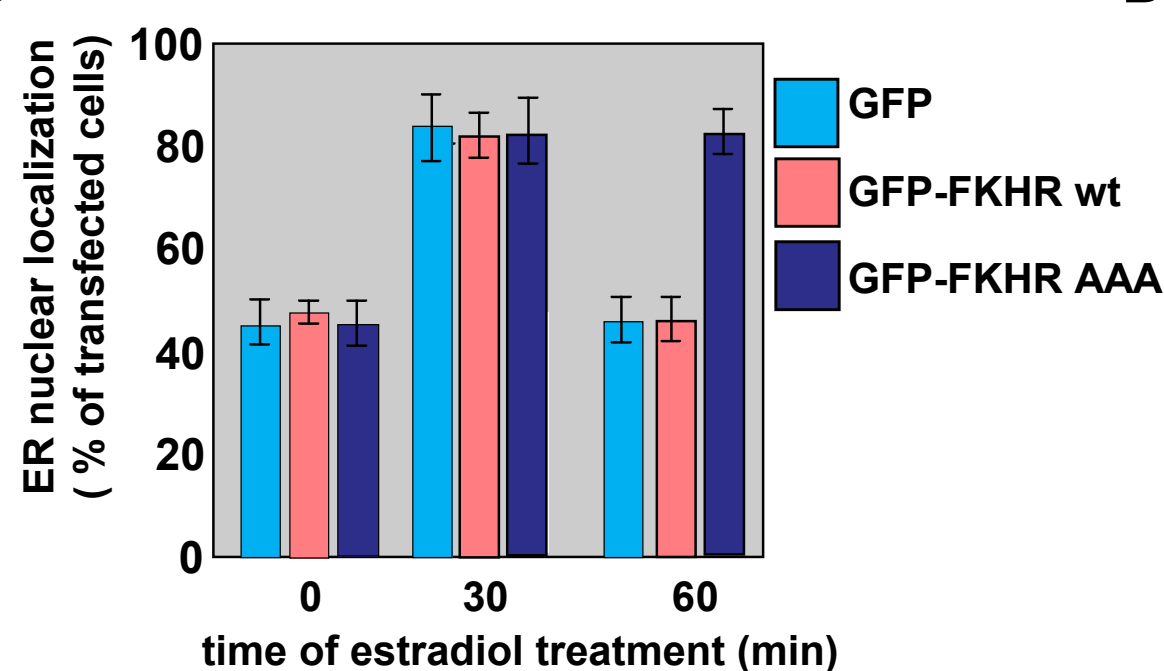

B

D
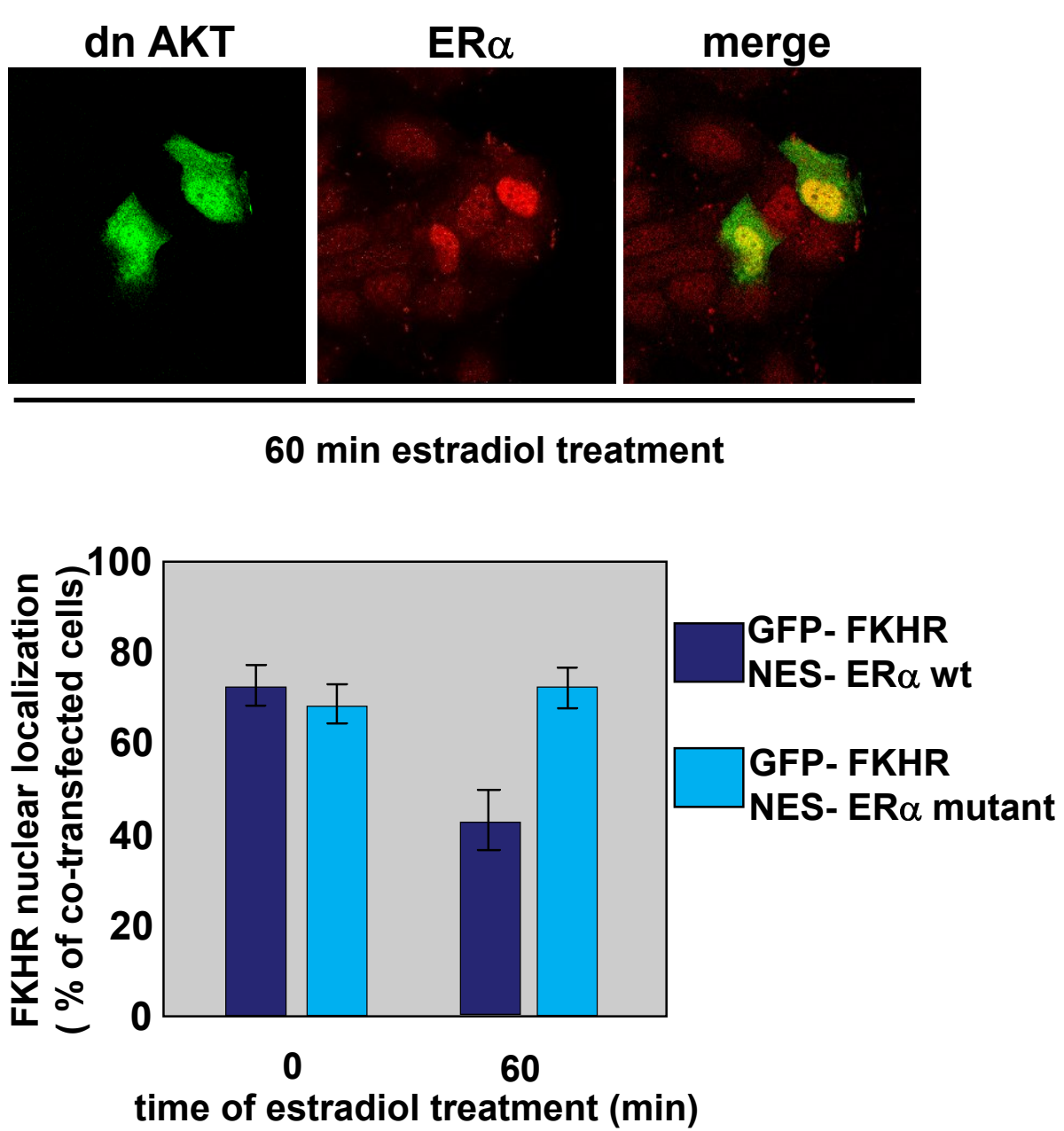

E

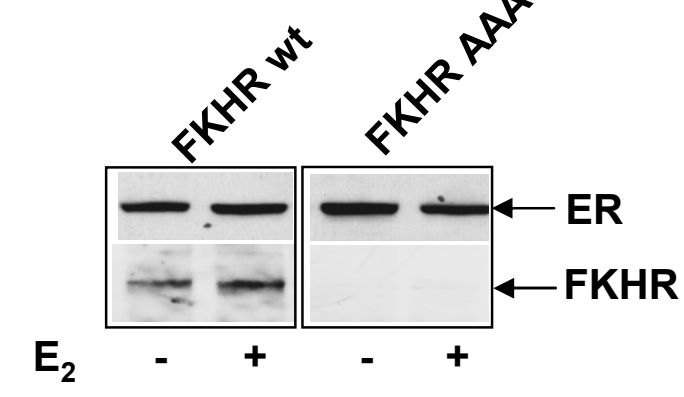

Fig. 2 


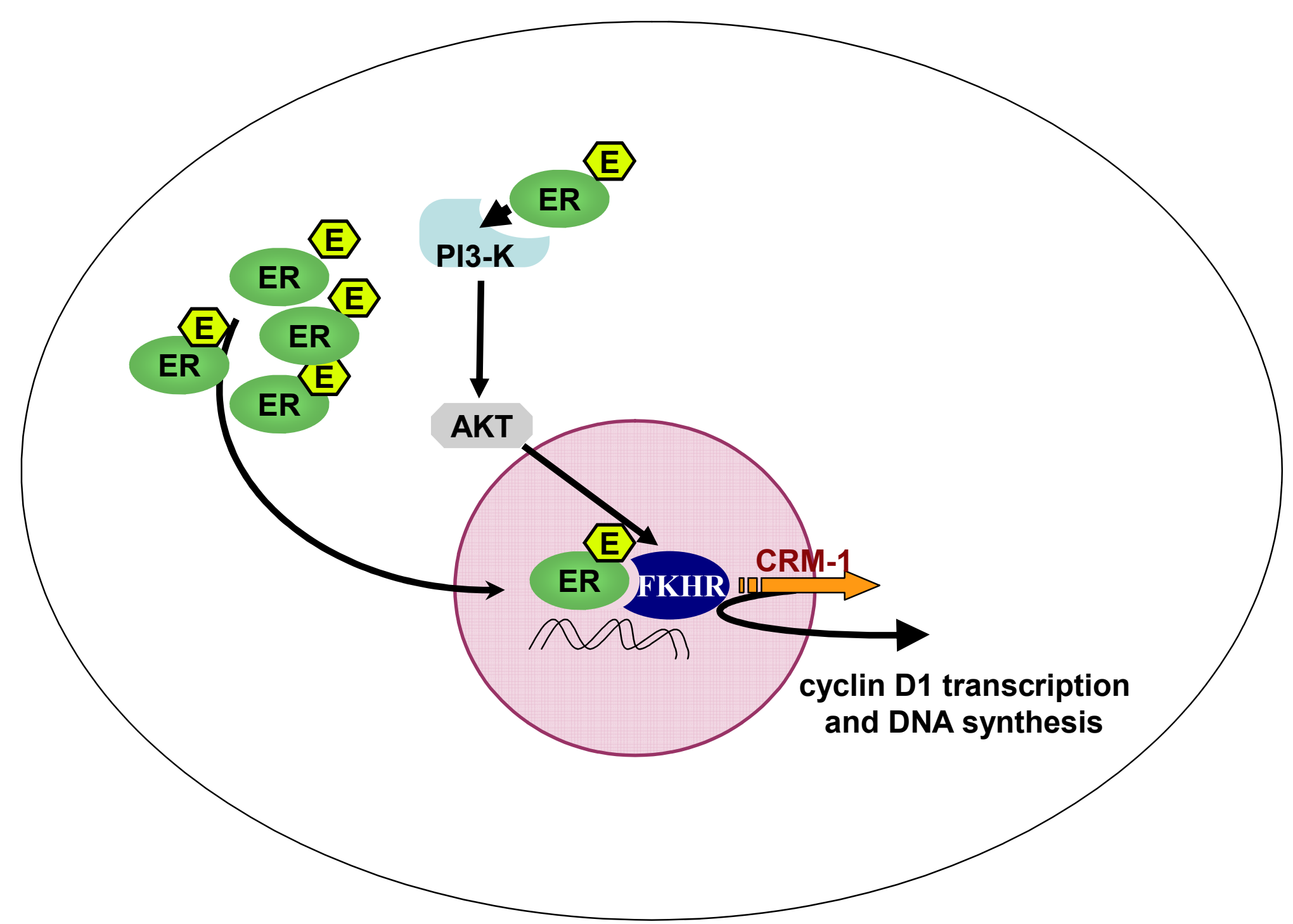

Fig. 3 